Revista Verde de Agroecologia e Desenvolvimento Sustentável

http://www.gvaa.com.br/revista/index.php/RVADS

ARTIGO CIENTÍFICO

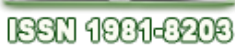

DOI: http://dx.doi.org/10.18378/rvads.v9i4.3169

\title{
Sistemas de captação de água "in situ" sobre crescimento de pinhão manso ${ }^{1}$
}

\section{Water catchment systems "in situ" about the growth of jatropha}

\author{
Eduardo M. O. Laime ${ }^{2}$, Pedro D. Fernandes ${ }^{3}$, Carlos A. V. de Azevedo ${ }^{3}$, José A.C. Wanderley ${ }^{2}$, Anderson Bruno A. de \\ Andrade
}

Resumo: O pinhão-manso (Jatropha curcas L.) é uma planta oleaginosa, da família das euforbiáceas, nativa das Américas e, atualmente, considerada uma alternativa para produção de biodiesel, exigente a insolação e resistente à seca. Nesta pesquisa, os estudos foram voltados para a avaliação do desenvolvimento da cultura do pinhão-manso, testando técnicas de plantio que contribuem para maior eficiência de captação de água de chuvas in situ. O experimento foi desenvolvido nas instalações da Estação Experimental do Instituto Nacional do Semiárido - INSA, localizada no município de Campina Grande-PB. O delineamento estatístico utilizado foi em blocos casualizados, com três repetições, sendo estudados cinco técnicas de captação de água in situ. Ao longo do ciclo as variáveis de crescimento são beneficiadas pelas formas de preparação do solo, para favorecer a captação de água in situ, em comparação ao tratamento com ausência de técnica de captação.

Palavras-chave: jatropha curcas, técnicas de plantio, umidade do solo, semiárido.

Abstract: The jatropha (Jatropha curcas L.) is an oilseed plant of the uphorbiaceae family, native to the Americas and is currently considered an alternative for biodiesel production, demanding heatstroke and drought resistant. In this research, the studies were designed to evaluate the development of culture of jatropha, testing, planting techniques that contribute to greater efficiency of rain water harvesting in situ. The experiment was conducted on the premises of the Experimental Station of the National Institute of Semiarid - INSA, located in Campina Grande-PB. The statistical outline utilized was in randomized blocks with three replications and studied five techniques of catchment of rainwater in situ. Throughout the growth cycle variables are benefited by the forms of soil preparation, to promote water harvesting in situ, compared to treatment with no technical catchment.

Key words: jatropha curcas, planting techniques, soil moisture, semiarid.

\footnotetext{
*autor para correspondência

Recebido para publicação em 21/08/2013; aprovado em 30/11/2014

${ }^{1}$ Projeto de pesquisa financiado pelo $\mathrm{CNPq}$

${ }^{2}$ Eng. Agronomo, Doutorando em Engenharia Agrícola/UFCG,

${ }^{3}$ DEAg/UFCG. (83) 2101 1185. Email: cazevedo@ deag.ufcg.edu.br

${ }^{4}$ Mestrando do programa de Sistemas Agroindustriais da CCTA/UFCG. E-mail: bdeandrade3@gmail.com
} 


\section{INTRODUÇÃO}

O pinhão-manso (Jatropha curcas L.), planta da família das euforbiáceas, é um arbusto com até $4 \mathrm{~m}$ de altura distribuído em regiões tropicais de todo o globo, inclusive no Brasil. Cresce rapidamente em solos pedregosos e de baixa umidade. Muitas vezes é cultivado como cerca viva mas seu maior emprego está na medicina popular. As sementes fornecem de 50 a $52 \%$ de óleo, extraído com solventes ou 32 a 35\%, em caso de extração por prensas (Peixoto, 1973).

Diante da preocupação atual com o efeito estufa, o aquecimento global e a escassez das reservas mundiais de combustível fóssil, o pinhão-manso tem despertado o interesse dos produtores, do governo e das instituições de pesquisa. Desta forma, com a possibilidade do uso do óleo de pinhão-manso para a produção de biodiesel, abrem-se amplas perspectivas para o aumento das áreas de plantio, com esta cultura, no semiárido nordestino (Arruda et al., 2004).Segundo Silva et al. (1993) em função da grande variação das chuvas registradas nas unidades geoambientais, identificadas na região semiárida do Nordeste brasileiro, é de fundamental importância o preparo do solo com técnicas de captação de água de chuva in situ, visando assegurar os cultivos implantados em regime de sequeiro, principalmente para amenizar os efeitos do déficit hídrico ocorrido em anos de pouca precipitação pluviométrica.

Pouco se conhece sobre a bioquímica e a fisiologia desta planta; não existem cultivares definidas e alguns aspectos agronômicos ainda carecem de investigação como, por exemplo, a densidade ideal de plantas e a configuração de plantio (Beltrão, 2006). Entretanto, com a possibilidade do uso de óleo de pinhão-manso para a produção do biodiesel, novas e amplas perspectivas se abrem para o aumento das áreas de plantio com esta cultura no semiárido nordestino. A literatura disponível relativa à cultura do pinhão-manso ainda é bastante escassa, pois passou a ser objeto de maior interesse nos últimos anos, haja vista a futura decadência do petróleo e pela possibilidade de serem usados óleos vegetais como combustíveis.

Nesta pesquisa os estudos foram voltados para a avaliação do desenvolvimento da cultura do pinhão-manso, testando-se técnicas de plantio que contribuem para maior eficiência de captação de água de chuvas in situ.

\section{MATERIAL E MÉTODOS}

O experimento foi desenvolvido nas instalações da Estação Experimental do Instituto Nacional do Semiárido INSA, localizada no município de Campina Grande, PB, correspondente à região fisiográfica Cariris Velhos (entre municípios de Campina Grande e Boa Vista) do Estado da Paraíba, com as seguintes coordenadas geográficas: latitude $07^{\circ} 27^{\prime} \mathrm{S}$, longitude $35^{\circ} 95^{\prime} \mathrm{W}$ e altitude média $550 \mathrm{~m}$. As mudas foram formadas em sacos de polietileno $(30 \times 15 \mathrm{~cm})$ na Estação Experimental do Instituto Nacional de Semiárido INSA, a partir de sementes cedidas pelo Instituto Fazenda Tamanduá, localizada no município de Santa Teresinha, PB, em pleno sertão paraibano, atualmente detentora de plantios de pinhão-manso. A semeadura foi realizada após seleção e eliminação de sementes defeituosas ou com danos mecânicos.

As sementes foram semeadas nos sacos preenchidos com substrato orgânico esterilizado e terra vegetal, aproximadamente a $2 \mathrm{~cm}$ de profundidade; a umidade foi mantida em capacidade de campo para possibilitar a seleção das plantas mais vigorosas por ocasião do transplantio.

$\mathrm{O}$ transplantio das mudas foi realizado no período em que as chuvas se iniciam na região. $O$ plantio foi em covas com as dimensões 40 × $40 \mathrm{~cm}$ de abertura e $50 \mathrm{~cm}$ de profundidade.

As estruturas de preparo de solo constaram de sulcos, camalhões e bacias, em nível, com $25 \mathrm{~cm}$ de profundidade ou de altura; a bacia foi formada puxando-se o solo de dentro e de fora da bacia, formando um camalhão circular. Os sulcos, fechados no seu final, e os camalhões funcionaram como áreas de captação e foram construídos obedecendo as curvas de nível do terreno. Foi comum a todos os tratamentos a incorporação de 3 litros de esterco de gado bovino por cova, uma forma de aumentar a capacidade de retenção de umidade. O espaçamento foi de $3 \times 2 \mathrm{~m}$, uma planta por cova.

Os tratamentos foram os seguintes:

1- plantio na linha dos sulcos em nível, abertos, situando-se a muda dentro do sulco;

2- plantio na linha dos sucos em nível, barrados entre uma planta e outra a $40 \mathrm{~cm}$ da planta, situando-se a muda dentro do sulco;

3- plantio na linha dos sulcos em camalhões em nível, plantando-se as mudas no camalhão;

4- plantio na linha dos sulcos em camalhões em nível, plantando-se as mudas dentro do sulco, na base do camalhão;

5- formação de bacias de 1 metro de diâmetro com o plantio da muda no centro;

6- testemunha, sem estrutura especial para captação de água.

O experimento foi distribuído em blocos casualizados, com 5 tratamentos de preparo de solo, mais uma testemunha sem técnica de preparação: T1, T2, T3, T4, T5 e T6 (testemunha), com 3 repetições. A parcela foi constituída de 4 filas de 5 plantas, no espaçamento de $3 \times 2 \mathrm{~m}$, uma planta por cova, considerando-se como úteis as 2 fileiras centrais, cada uma com 3 plantas úteis, tendo como bordaduras as duas plantas das extremidades da fileira. Portanto, foram 6 plantas úteis por parcela.

Em cada parcela do experimento foi introduzido no solo um tubo de acesso, para leitura da umidade do solo com o auxílio de TDR.

Fez-se, por ocasião da aplicação dos tratamentos a avaliação da altura de planta, diâmetro caulinar e área foliar a cada 60 dias. A altura da planta (AP) foi medida $(\mathrm{cm})$ entre o colo da planta e a extremidade do broto terminal da haste principal, com o auxílio de fita métrica; o diâmetro foi avaliado com paquímetro digital, cujas leituras $(\mathrm{mm})$ foram realizadas no colo da planta a uma altura aproximada de $5 \mathrm{~cm}$ do solo.

Na determinação do número de folhas por planta e na estimativa da 'AF', consideraram-se apenas folhas completamente abertas, com pelo menos $3 \mathrm{~cm}$ de comprimento (nervura principal). A 'AF' individual foi estimada com base na Eq. 1, descrita a seguir, proposta por Severino et al. (2006):

$\mathrm{AF}=0,89 \mathrm{P} 2$

em que:

$\mathrm{AF}$ - Área foliar (m2)

$\mathrm{P}$ - Comprimento da nervura principal (m). 
Transcorrido o período experimental os dados foram tabulados e submetidos a análises de variância, de médias, de regressão polinomial e teste "F", utilizando-se do programa SISVAR, conforme metodologia de Ferreira (2000).

\section{RESULTADOS E DISCUSSÃO}

\section{Altura de Plantas (AP)}

Observa-se, através da Tabela 1 , que na variável altura de plantas ao longo do tempo estudado, as técnicas de captação de água in situ promoveram efeitos significativos $(\mathrm{p}<0,01)$ favorecendo o crescimento das plantas.
Os dados de AP nos tratamentos constando de plantio em sulcos abertos (T1), plantio em bacias (T5) e ausência de técnicas de captação (T6) se ajustaram ao modelo linear e quadrático, com significância variando entre $p<0,01$ e $p<0,05$, optando-se pelo linear, com base nos valores de R2 (Figura 1).

Com base nas equações contidas na Figura 1, os valores médios de altura das plantas, ao longo das 10 (dez) avaliações, foram 132,36, 130,65 e $115,39 \mathrm{~cm}$, para os tratamentos T1, T5 e T6, respectivamente; assim, pode-se notar, ao final da pesquisa, um decréscimo maior que $12 \%$ entre os tratamentos T1 e T6.

Tabela 1. Resumo das análises de regressão da altura de planta (AP) do pinhão-manso, em função de técnicas de captação de água in situ ao longo do tempo. Campina Grande, PB, 2012.

\begin{tabular}{|c|c|c|}
\hline \multirow[t]{2}{*}{ Fonte de variação } & \multirow[t]{2}{*}{ GL } & Quadrados Médios \\
\hline & & Altura de Plantas \\
\hline Tratamentos & 5 & $1417,1939 * *$ \\
\hline Tempo & 9 & $1026,2946 * *$ \\
\hline Regressão Linear & 1 & $8232,8666^{* *}$ \\
\hline Regressão Quadrática & 1 & $525,9054^{*}$ \\
\hline Regressão Cúbica & 1 & $231,4585^{\text {ns }}$ \\
\hline Regressão $4^{\circ}$ grau & 1 & $205,1554^{\mathrm{ns}}$ \\
\hline Desvio de Regressão & 1 & $8,2532^{\mathrm{ns}}$ \\
\hline Tempo x Tratamento & 45 & $4,9018^{\mathrm{ns}}$ \\
\hline Blocos & 2 & 741,2629 \\
\hline Resíduo & 118 & 89,9493 \\
\hline $\mathrm{CV}(\%)$ & & 7,44 \\
\hline Tratamentos & & Médias (cm) \\
\hline $\mathrm{T} 1$ & & $132,3666 a$ \\
\hline $\mathrm{T} 2$ & & $131,6777 \mathrm{a}$ \\
\hline $\mathrm{T} 3$ & & $122,9166 b$ \\
\hline $\mathrm{T} 4$ & & $131,6833 a$ \\
\hline T5 & & $130,6555 \mathrm{a}$ \\
\hline T6 & & $115,3916 \mathrm{c}$ \\
\hline
\end{tabular}

Segundo Santos (2008) em sua pesquisa sobre fenologia e capacidade fotossintética do pinhão-manso em diferentes épocas do ano, no estado de Alagoas, aos seis meses de idade, o pinhão-manso tinha altura média de $30 \mathrm{~cm}$ e $23 \mathrm{~mm}$ de diâmetro caulinar e que, aos com 21 meses de idade, atingiu altura média de $147 \mathrm{~cm}$ e diâmetro caulinar de $80 \mathrm{~mm}$, valores aproximados aos registrados neste trabalho.

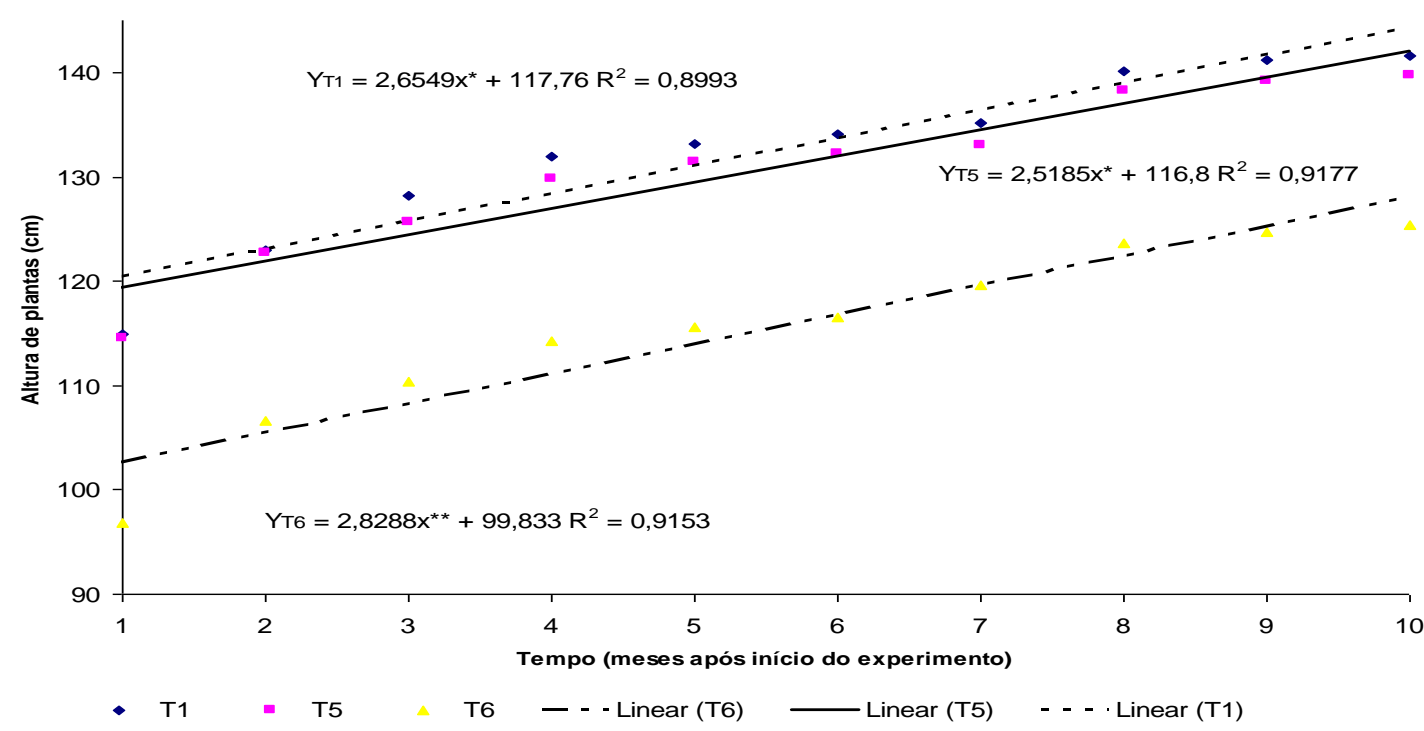

Figura 1. Valores médios da altura de plantas (AP) do pinhão-manso ao longo do tempo, em função de técnicas de captação de água in situ. Campina Grande, PB, 2012. 


\section{Diâmetro Caulinar (DC)}

Nota-se, através da Tabela 2, efeito significativo $(\mathrm{p}<0,01$ e $\mathrm{p}<0,05)$ das técnicas de captação de água in situ sobre o diâmetro de plantas, em todos os tratamentos; com a decomposição dos graus de liberdade do fator tratamento em componentes de regressão polinomial, verificou-se ter sido afetado o diâmetro caulinar pelas técnicas de captação de água, ao longo do experimento. Com base no maior valor do coeficiente de determinação (R2) optou-se pelo modelo linear apresentando-se as equações para os vários tratamentos, ao longo do período experimental, na Figura 2; ao longo do tempo destacou-se o cultivo das plantas em camalhão (T3), ao serem registrados valores mais altos de diâmetro do caule, chegando a alcançar de $66,95 \mathrm{~mm}$.

Tabela 2. Resumo das análises de regressão do diâmetro caulinar (DC) do pinhão-manso, em função de técnicas de captação de água in situ ao longo do tempo. Campina Grande, PB, 2012

\begin{tabular}{ccc}
\hline Fonte de variação & GL & Quadrados Médios \\
\cline { 2 - 3 } & & Diâmetro Caulinar \\
\hline Tratamentos & $\mathbf{5}$ & $208,8214^{* *}$ \\
\hline Tempo & $\mathbf{9}$ & $512,1064^{* *}$ \\
\hline Regressão Linear & 1 & $3836,2976^{* *}$ \\
Regressão Quadrática & 1 & $474,0800^{* *}$ \\
Regressão Cúbica & 1 & $173,9045^{*}$ \\
Regressão 4 ${ }^{\text {o grau }}$ & 1 & $58,1274^{\text {ns }}$ \\
Desvio de Regressão & 1 & $13,3097^{\text {ns }}$ \\
\hline Tempo x Tratamento & $\mathbf{4 5}$ & $2,6736^{\text {ns }}$ \\
\hline Blocos & $\mathbf{2}$ & 65,1180 \\
\hline Resíduo & $\mathbf{1 1 8}$ & 25,4208 \\
\hline CV(\%) & & 8,54 \\
\hline Tratamentos & & Médias (mm) \\
\hline T1 & & $60,3645 \mathrm{a}$ \\
T2 & & $59,0037 \mathrm{a}$ \\
T3 & $61,8793 \mathrm{a}$ \\
T4 & & $59,1425 \mathrm{a}$ \\
T5 & $59,8877 \mathrm{a}$ \\
T6 & & $54,1145 \mathrm{~b}$ \\
\hline ** * ns Significativo a 1\%, 5\% e não significativo, respectivamente, pelo Teste F
\end{tabular}

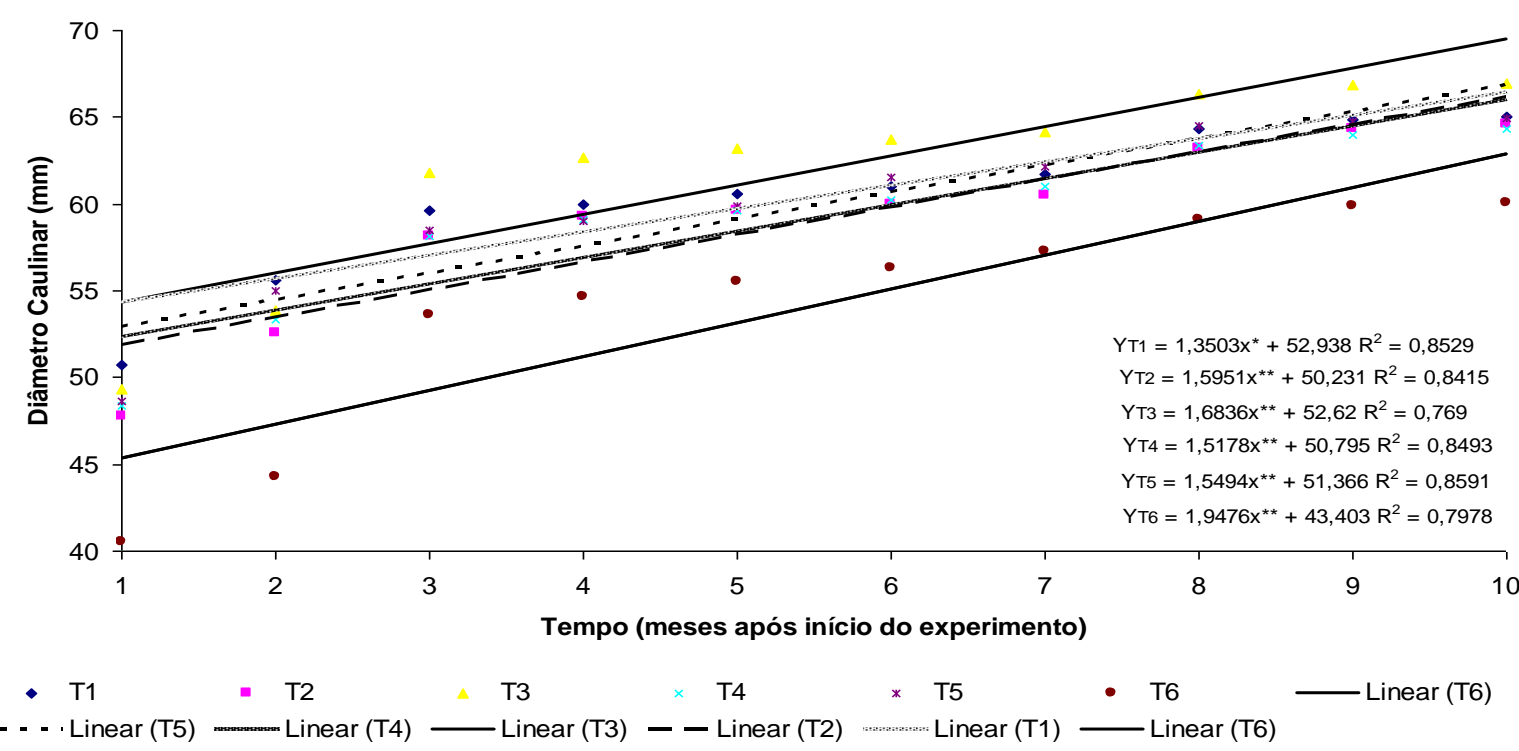

Figura 2. Valores médios da diâmetro caulinar (DC) do pinhão-manso ao longo do tempo, em função de técnicas de captação de água in situ. Campina Grande, PB, 2012. 
À semelhança da variável altura de plantas, os menores valores de diâmetro caulinar foram observados no tratamento sem estrutura especial de captação (T6).O crescimento do caule das plantas, em diâmetro, ocorreu de forma contínua ao longo de todo o estudo, conforme o tipo de tratamento testado. Os valores médios de diâmetro caulinar das plantas nas 10 (dez) avaliações, foram 60,36, 59,00, $61,87,59,14,59,88$ e $54,11 \mathrm{~mm}$, para os tratamentos $\mathrm{T} 1, \mathrm{~T} 2$,
T3, T4, T5 e T6, respectivamente, sem se diferenciarem significativamente entre si, os cinco primeiros tratamentos.

\section{Número de folhas (NFl)}

Os dados do resumo das análises de regressão de número de folhas, ao longo do tempo, estão apresentados na Tabela 3, observando-se efeito significativo das técnicas de captação de água in situ sobre a variável.

Tabela 3. Resumo das análises de regressão do número de folhas (NFl) do pinhão-manso, em função de técnicas de captação de água in situ ao longo do tempo. Campina Grande, PB, 2012

\begin{tabular}{|c|c|c|}
\hline \multirow[t]{2}{*}{ Fonte de variação } & \multirow[t]{2}{*}{ GL } & \multirow{2}{*}{$\begin{array}{l}\text { Quadrados Médios } \\
\text { Número de Folhas }\end{array}$} \\
\hline & & \\
\hline Tratamentos & 5 & $60,6235 * *$ \\
\hline Tempo & 9 & $129,4969 * *$ \\
\hline Regressão Linear & 1 & $3,2152^{\mathrm{ns}}$ \\
\hline Regressão Quadrática & 1 & $244,6431 * *$ \\
\hline Regressão Cúbica & 1 & $159,4927 * *$ \\
\hline Regressão $4^{\circ}$ grau & 1 & $444,5287 * *$ \\
\hline Desvio de Regressão & 1 & $62,7184 * *$ \\
\hline Tempo x Tratamento & 45 & $0,8193^{\mathrm{ns}}$ \\
\hline Blocos & 2 & 13,9279 \\
\hline Resíduo & 118 & 5,8944 \\
\hline $\mathrm{CV}(\%)$ & & 15,17 \\
\hline Tratamentos & & Médias \\
\hline $\mathrm{T} 1$ & & $\begin{array}{c}16,3325 \mathrm{ab} \\
(285.7111)\end{array}$ \\
\hline $\mathrm{T} 2$ & & $\begin{array}{c}15,7396 b \\
(254.8111)\end{array}$ \\
\hline $\mathrm{T} 3$ & & $\begin{array}{c}17,9898 \mathrm{a} \\
(336.0000)\end{array}$ \\
\hline $\mathrm{T} 4$ & & $\begin{array}{c}16,0959 b \\
(266.5111)\end{array}$ \\
\hline $\mathrm{T} 5$ & & $\begin{array}{c}16,2698 \mathrm{ab} \\
(275.8333)\end{array}$ \\
\hline T6 & & $\begin{array}{c}13,5743 \mathrm{c} \\
(188.4999)\end{array}$ \\
\hline
\end{tabular}

${ }^{\mathrm{a}}$ Dados transformados em $\sqrt{\mathrm{x}}+0,5$, entre parênteses estão os dados originais. ** Significativo a $1 \%$ pelo Teste $\mathrm{F}$

Os dados de NFl se ajustaram a modelos de regressão até o $4^{\circ}$ grau $(\mathrm{p}<0,01)$. Durante o período do experimento ocorreram quatro meses em que os valores da variável número de folhas e área foliar começaram a decair, correspondendo ao período seco. No início do período chuvoso o número de folhas e a área foliar começaram a aumentar, fatos esses importantes para se entender a fisiologia e a fenologia do pinhão, durante o experimento.

De acordo com Santos (2008) a abscisão foliar se inicia no final do período chuvoso e durante a época seca. Já para Sartunino et al. (2005) o pinhão-manso tem comportamento decíduo, cujas folhas caem, em parte ou totalmente, no final da época seca ou durante a estação chuvosa. Segundo esses autores, o pinhão-manso permanece em repouso até o começo da primavera ou da época das chuvas nas regiões secas. Assim, as espécies podem ser classificadas como decíduas quando apresentam abscisão e produção de folhas concentradas em determinada época, ficando por um período de tempo quase ou totalmente sem folhas (Santos \& Takaki, 2005).

Os maiores valores de número de folhas foram encontrados no tratamento em que o plantio foi feito em camalhões (T3), (Figura 3). Pedroni et al. (2002) e Bianchini et al. (2006) sugerem que outros fatores, tais como temperatura, fotoperíodo e disponibilidade de água, também podem influenciar no crescimento das plantas.

Para Saturnino et al. (2005) conforme a região o desenvolvimento inicial das mudas de pinhão-manso pode ser influenciado pela época de chuvas, ventos dominantes e outras ocorrências climáticas típicas de cada local. 


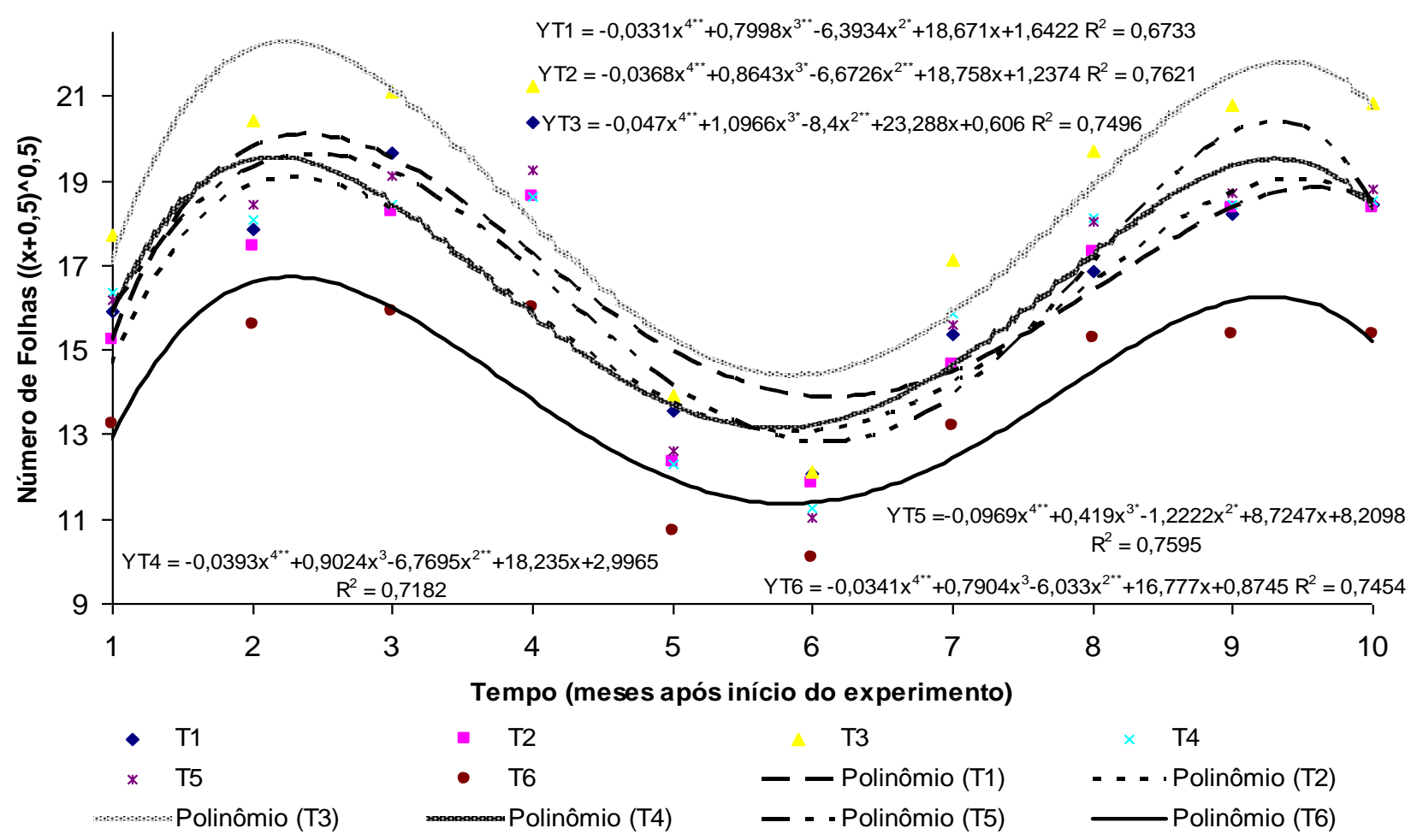

Figura 3. Valores médios do número de folhas (NFl) do pinhão-manso ao longo do tempo, em função de técnicas de captação de água in situ. Campina Grande, PB, 2012.

\section{Área Foliar (AF)}

Nota-se, através da Tabela 4, efeito significativo $(\mathrm{p}<0,01)$ das técnicas de captação de água in situ sobre a área foliar de plantas, em todos os tratamentos. Decompondo os graus de liberdade do fator tratamento em componentes de regressão polinomial, verificou-se que a AF foi afetada em todos os graus de regressão, pelas técnicas de captação de água, ao longo do experimento.

Observando a Figura 4 percebe-se que houve semelhança entre a variável número de folhas e área foliar, como se esperava. No início do período chuvoso ocorreu aumento na área foliar da planta. Com o aumento de AF, aumenta a interceptação luminosa e deve aumentar a eficiência de uso da radiação fotossinteticamente ativa, o que ocasiona uma aceleração na taxa de crescimento em condições ambientais favoráveis (Humphreys, 1966; Brown \& Blaser, 1968).

A importância da área foliar de uma cultura é amplamente conhecida por ser um parâmetro indicativo de produtividade pois o processo fotossintético depende da interceptação da energia luminosa e sua conversão em energia química. De acordo com Leong (1980) a eficiência fotossintética depende da taxa fotossintética por unidade de área foliar e da interceptação da radiação solar as quais, entre outros aspectos, são influenciadas pelas características da arquitetura da copa e da dimensão do sistema fotoassimilador. Vale ressaltar, ainda, que o conhecimento da área foliar da planta possibilita a estimativa da perda de água uma vez que as folhas são os principais órgãos que participam no processo transpiratório, responsável pela troca gasosa com o ambiente (Pereira et al., 1997).
Os melhores valores em área foliar foram encontrados no tratamento em que o plantio foi feito em sulco, barrados entre plantas (T2).

Tabela 4. Resumo das análises de regressão da área foliar (AF) do pinhão-manso, em função de técnicas de captação de água in situ ao longo do tempo. Campina Grande, PB, 2012

Fonte de variação GL Quadrados Médios

\begin{tabular}{ccc}
\cline { 2 - 3 } & & Área Foliar \\
\hline Tratamentos & $\mathbf{5}$ & $0,000548^{* *}$ \\
\hline Tempo & $\mathbf{9}$ & $0,002227^{* *}$ \\
\hline Regressão Linear & 1 & $0,005793^{* *}$ \\
Regressão Quadrática & 1 & $0,000996^{* *}$ \\
Regressão Cúbica & 1 & $0,006353^{* *}$ \\
Regressão 4 ${ }^{\text {o grau }}$ & 1 & $0,002566^{* *}$ \\
Desvio de Regressão & 1 & $0,000868^{* *}$ \\
\hline Tempo x Tratamento & $\mathbf{4 5}$ & $0,000060^{\text {ns }}$ \\
\hline Blocos & $\mathbf{2}$ & 0,000074 \\
\hline Resíduo & $\mathbf{1 1 8}$ & 0,000052 \\
\hline CV(\%) & & \\
\hline Tratamentos & & Médias $\left(\mathrm{m}^{2}\right)$ \\
\hline T1 & & $0,0803 \mathrm{bc}$ \\
T2 & & $0,0861 \mathrm{a}$ \\
T3 & & $0,0811 \mathrm{abc}$ \\
T4 & & $0,0790 \mathrm{~cd}$ \\
T5 & & $0,0856 \mathrm{ab}$ \\
T6 & & $0,0748 \mathrm{~d}$ \\
\hline
\end{tabular}

**, ${ }^{\mathrm{n}}$ Significativo a $1 \%$ e não significativo, respectivamente, pelo Teste $\mathrm{F}$ 


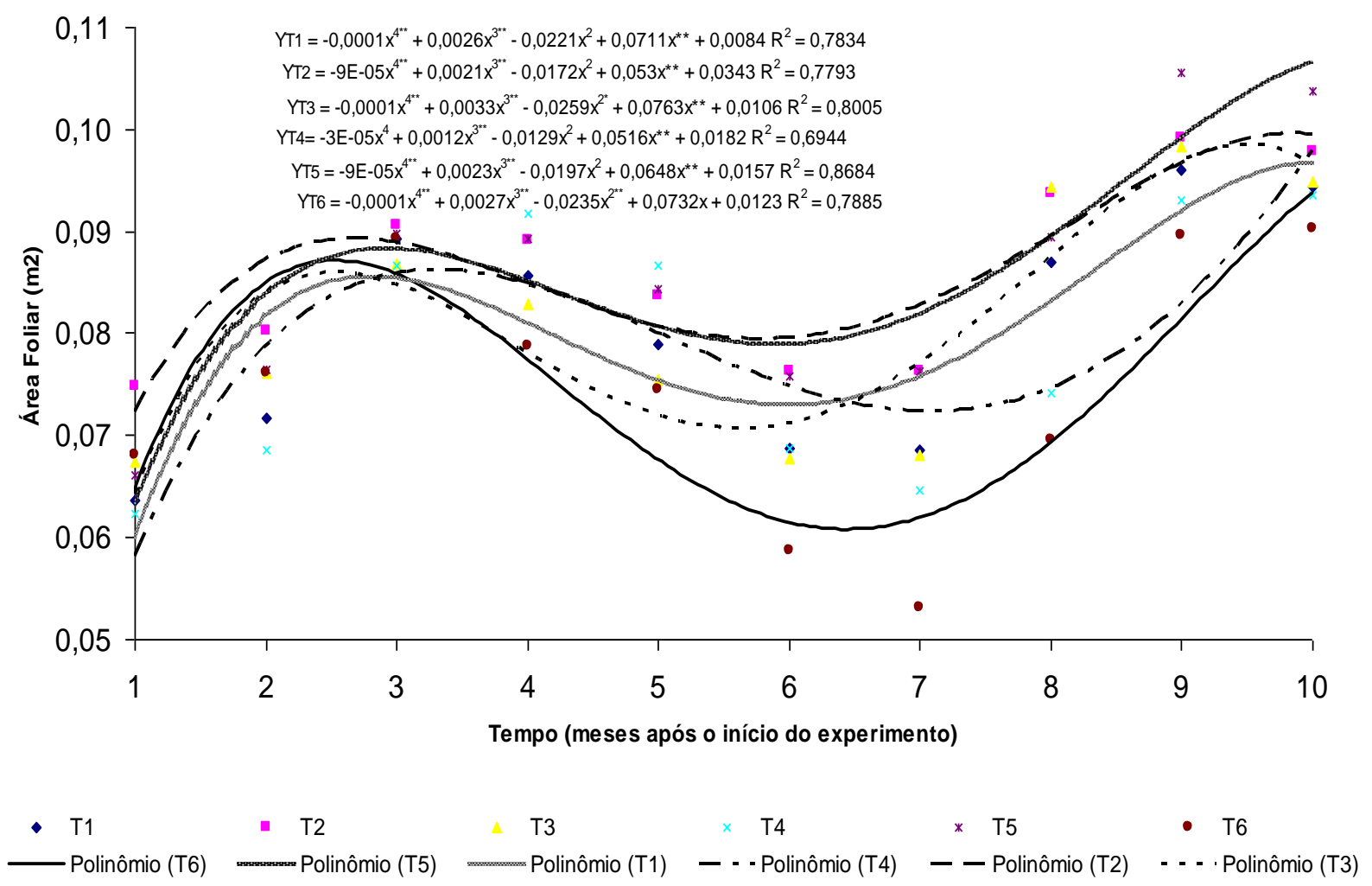

Figura 4. Valores médios da área foliar (AF) do pinhão-manso ao longo do tempo, em função de técnicas de captação de água in situ. Campina Grande, PB, 2012.

\section{CONCLUSÕES}

Ao longo do ciclo as variáveis de crescimento são beneficiadas pelas formas de preparação do solo, para favorecer a captação de água in situ, em comparação ao tratamento com ausência de técnica de captação;

A técnica de captação com plantio em camalhões em nível, plantando as mudas no camalhão (T3), apresentou melhor desempenho em comparação as demais.

\section{REFERÊNCIAS BIBLIOGRÁFICAS}

ARRUDA, F. P. de; BELTRÃO, N. E. de M.; ANDRADE, A. P. de; PEREIRA, W. E.; Severino, L. S. Cultivo do pinhão-manso (Jatropha curcas L.) como alternativa para o Semiárido Nordestino. Revista Brasileira de Oleaginosas e Fibrosas, v.8, n.1, p.789-799, 2004.

BELTRÃO, N. E. de M. Considerações gerais sobre o pinhão-manso (Jatropha curcas L.) e a necessidade urgente de pesquisas, desenvolvimento e inovações tecnológicas para esta planta as condições brasileiras. Campina Grande: EMBRAPA. 2006. 4p.

BIANCHINI, E.; PIMENTA, J. A.; SANTOS, F. A. M. Fenologia de Chrysophyllum gonocarpum (Mart. \& Eichler) Engl.(Sapotaceae) em floresta semidecídua do Sul do Brasil. Revista Brasileira de Botânica, v. 29, n. 4, p. 595-602, 2006.
BROWN, R.H.; BLASER, R.E. Leaf area index in pasture growth. Herbage Abstracts, v.38, n.1, p.1-9, 1968.

FERREIRA, P. V. Estatística experimental aplicada à agronomia. 2ed. Revisada e ampliada. Maceió: UFAL/EDUFAL/FUNDEPES, 2000. 437p.

HUMPHREYS, L.R. Subtropical grass growth: II Effects of variation in leaf area index in the field. Queenland Journal of Agricultural and Animal Sciences, v.23, p.388-358, 1966.

LEONG, W. Canopy modification and its effects on the growth and yield of Hevea brasiliensis Muell. Arg. 1980. 283 p. Thesis (Ph.D.) - Faculty of Agriculture Sciences of Ghent, Ghent.

PEDRONI, F.; MARYLAND, S.; SANTOS, F. A. M. Fenologia da copaíba (Copaifera langsdorffii Desf. Leguminosae, Caesalpinioideae) em uma floresta semidecídua no sudoeste do Brasil. Revista Brasileira de Botânica, v. 25, n. 2, p. 183-194, 2002.

PEIXOTO, A. R. Plantas oleaginosas arbóreas. São Paulo, Nobel, 1973.

PEREIRA, A. R.; VILLA NOVA, N. A.; SEDIYAMA, G. C. Evapotranspiração. Fundação de Estudos Agrários Luís de Queiroz, 1997. 183p.

SANTOS, C. M. dos. Fenologia e capacidade fotossintética do pinhão-manso (Jatropha curcas L.) em diferentes épocas do ano no estado de alagoas, 2008. 79p. 
(Dissertação de Mestrado) - Universidade Federal de Alagoas, Rio Largo. SANTOS, D. L.; TAKAKI, M. Fenologia de Cedrela fissilis Vell. (Meliaceae) na região rural de Itirapina, SP, Brasil. Acta Botanica Brasilica, v. 19, n. 3, p. 625-632, 2005.

SATURNINO, H.M.; PACHECO,D.D.; KAKIDA, J.; TOMINAGA, N.; GONÇALVES, N. P. Cultura do pinhão-manso (Jatrofa curcas L.). Informe agropecuário, Belo Horizonte, v. 26, n. 229, p.44 - 78, 2005.

SEVERINO, L. S.; VALE, L. S.; BELTRÃO, N. E. de M. In: I Congresso de Rede Brasileira de Tecnologia do Biodiesel. Anais..., Brasília, p.73-77, 2006.

SILVA, F. B. R. e.; RICHÉ,G. R.; TONNEAU, J. P.; SOUZA NETO, N. C. de.; BRITO, L. T. de L.; CORREIA, R. C.;

CAVAlCANTE, A. C.; SILVA, F. H. B. B. da.; SILVA, A. B. da.; ARAÚJO FILHO, J. C. de. Zoneamento agroecológico do Nordeste: diagnóstico do quadro natural e agrossócioeconômico. Petrolina-PE: EMBRAPA - CPATSA/Recife: EMBRAPA - CNPS, Coordenadoria Regional Nordeste, v.1. 1993. 